\title{
Public Private Partnership Benefits in Delivering Public Facilities in Malaysia
}

\author{
Sapri M. ${ }^{1, a}$, Hariati A.H. ${ }^{2}$, Sheau Ting L. ${ }^{3}$ and Sipan I. ${ }^{4}$ \\ 1,3,4 Centre for Real Estate Studies, Universiti Teknologi Malaysia, 81310 UTM Johor Bahru, Johor, Malaysia \\ ${ }^{2}$ Faculty of Geoinformation and Real Estate, Universiti Teknologi Malaysia, 81310 UTM Johor Bahru, Johor, Malaysia
}

\begin{abstract}
The development of infrastructure in developing country such as Malaysia was increasingly founded by the Public -Private Partnership (PPP) scheme. Collaboration with private sector has become popular as a means to improve the delivery of public facilities. Yet, empirical evidence on how PPP initiative has benefits the delivery of public facilities within Malaysia context is lagging. The purpose of this paper is to identify and assess the perception of stakeholders on the benefits of adopting PPP in delivering public facilities in Malaysia. Literature review was carried out to identify PPP benefits, which were then incorporated into the questionnaire. The mean score and mean score ranking was conducted to assess the agreement level of stakeholders towards the PPP benefits. The overall findings show that the implementation of PPP has benefitted the delivery of public facilities in both financial and nonfinancial aspects. From the analysis, improvement in service quality is perceived as the top advantage followed by innovation in design and transfer of risk. The findings provide more informed basis on the rationale of PPP implementation and its potential in improving the delivery of public facilities within Malaysia context.
\end{abstract}

\section{Introduction}

Public facilities for education, recreation, health, safety, and communication are some of the essential community needs. The provision of these facilities is part of the major government responsibilities. Besides making the facilities available to everyone, the government also has to ensure the delivery process is conducted in an efficient way. However, government nowadays has a limited ability to respond to the increasing demand of public facilities. Factors such as scarce sources, macro economic instability, administrative inefficiencies and large skill gaps have restrained the government to deliver the services at a required level [1].

The pressure felt by the government has led to the implementation of public private partnership (PPP) scheme, which allowed the participation of private sectors in the provision of public facilities. Through this scheme, the government has entrust the private sector with the responsibility of designing, financing, building and operating of public facilities [2]. According to [3] private sector has greater expertise in managing complex projects, capable in delivering them on time and budged, as well as maintaining services thereafter. Therefore, PPP is considered as an effective approach to enhance project productivity through management efficiency and creative skills from business practice [4].

The reasons for adopting PPP may vary in different countries. [5] discovered that United Kingdom (UK) has implement PPP for the financial elements while Hong
Kong and Australia were more related to the overall performance of improving public projects. In Malaysia, the principal objectives of PPP implementation are to encourage private sectors participation, reduce government's expenditure and to improve the delivery of public facilities [6, 7]. PPP is adopted to increase efficiency, greater innovation and value-added services [8]. While the rationale for adopting PPP in Malaysia is well understood, it was discovered that assessment on the impact of PPP implementation is remain limited. Since the implementation of PPP is growing in Malaysia, initial investigation on how PPP so far has benefited the delivery of public facilities and services is thus desirable. Hence, this study aims to fill the gap. In order to offer some evidence on the present issues, this study has embarked on quantitative methods.

This paper is structured as follows; Section 2 discuss the development of PPP in Malaysia and Section 3 discuss advantages of PPP in delivering public facilities respectively. Section 4 offers the information regarding research method adopted in this study. Section 5 presents the results and discussion, while Section 6 concludes the findings of this study.

\section{Development of public private partnership implementation in Malaysia}

The concept of partnership between the public and private sectors in Malaysia has existed since 1980s. Malaysia government has taken a lot of initiatives to

\footnotetext{
a Corresponding author: maimunahsapri@utm.my
} 
foster the involvement of private sectors in delivering public facilities. These include the introduction of economic policies such as The Malaysian Incorporated Policy (1981), Privatisation Policy (1983), Guidelines on Privatisation (1985) and Privatisation Master Plan in 1991 [9]. As in United Kingdom (UK), privatisation programme has triggered the execution of PPP in Malaysia. Operation and Management Licence; Build, Operate and Transfer (BOT); Build, Operate, Own, Transfer (BOOT); and Lease-Sale are among the partnership arrangements that have started to be used [8]. The implementation of PPP until 2010 is mostly in construction, manufacturing, transport, storage and communication. Figure 1 shows the division of PPP projects according to sectors in Malaysia.

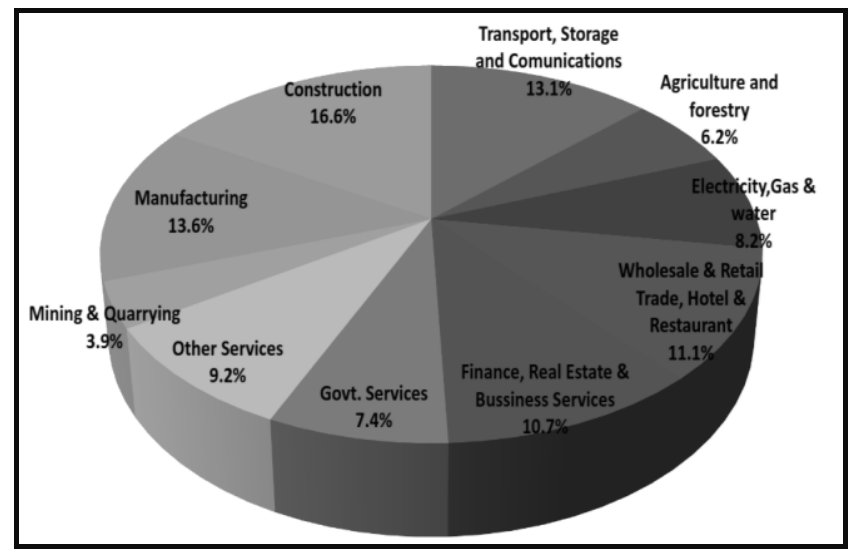

Figure 1. PPP project according to sectors from year 1983 - 2010. (Source: PPP Unit, Malaysia)

Malaysian government has officially announced The Private Finance Initiatives (PFI) Programme under PPP in the Ninth Malaysia Plan (2006). The introduction of PFI has become the spotlight for the overall implementation of PPP in Malaysia. It was reported in the Eleventh Malaysia Plan (2016-2020) that the private sectors participation especially via private investment is the lead of economic growth in Tenth Malaysia Plan (10MP). In Malaysia context, PFI is referred to;

'The transfer to the private sector the responsibility to finance and manage a package of capital investment and services including the construction, management, maintenance, refurbishment and replacement of the public sector assets which creates a standalone business. The private sector will create the asset and deliver a service to the public sector client. In return, the private sector will receive payment commensurate with the levels, quality and timeliness of the service provision throughout the concession period' [10]

In assessing the rational of PPP implementation, [11] discovered both public and private stakeholders perceived "to enhance private sector involvement in economic development" as the most important rational in adopting PPP in Malaysia. Besides, [12] found the attractive factors that encourage the adoption of PPP are include "facilitate creative and innovative approaches", "solve the problem of public sector budget restraint", "provide an integrated solution", "benefit local economic development" and "accelerate project development". Another in-depth investigation on PPP implementation by [13] indicated that the implementation of PPP/PFI in Malaysia have several distinctive aspect, which benefits the Malaysian citizen and enhance the sustainability of Malaysian infrastructure.

Parallel with the development, studies in regards to local implementation of PPP is actively being conducted in Malaysia. [14] conducted a research on the possible constrains that hinder the adoption of PPP in Malaysia. The results show that the obstacles that may make PPP less attractive are "lengthy delays in negotiation", "lack of government guidelines and procedures on PPP", "higher charge to direct users", "lengthy delays because of political debate" and "confusion over government objectives and evaluation criteria". A few studies also have been done on the most critical area of PPP which is value for money (VFM). [15] examined the factor that enhancing VFM achievement for PPP projects. The study concludes that five factors that enhance VFM include "competitive tender", "private sector technical innovation", "optimal use of asset/facility and project efficiency", "efficiency risk allocation and performancebased payment mechanism". By stressing the needs for VFM assessment in each phase of PPP project life cycle, study by [16] revealed that both public and private sectors perceived financial and non-financial aspects are vital elements to be captured in that process.

\section{Benefits of PPP in delivering public services}

PPP scheme has introduced a whole life approach where the involved parties are responsible to design, build, finance and operate public facilities for about 20-30 years. There is a long term consideration for whole life costing that includes capital cost, operating cost, maintenance cost, replacement cost and disposal cost [17]. The ultimate aim is to achieve value for money (VfM), which is 'the optimum combination of whole-life costs, benefit, risks, and quality (fitness for purpose) to meet the user's requirement and getting the best possible outcome at the lowest possible price'[18]. VfM also potrays how much cost savings are achieved when comparing PPP with traditional approach in delivering public facilities [19].

Private parties tend to seek accurate estimation for capital and operational costs as they bear a huge responsibility in the development and operational phase of PPP projects. Private sectors have the advantages in delivering public facilities at lower capital expenditure (Capex) and operational expenditure (Opex). According to [20], private sector was considered better at coordinating the activities for design, construction, finance, operations and maintenance at a lower cost compared to the government. Technical efficiency [21], better risk management, innovation and advance in technology [22] are among the factors that favour the 
private sectors to deliver an efficient Capex and Opex of projects.

The other reason of adopting PPP is to achieve time savings in project development. The expert owned by the private sectors allows them to expedite the development process. According to the [23] in so called 'fast-tract' design and construction of PPP, certain elements of construction work can be concurrently conducted with ongoing design phase of PPP projects. Construction firms have also been involved since design reviews process to spot any possibility that might delay the complete time of construction.

Besides faster delivery, better project governance is also to be expected in PPP implementation. Project governance is a framework that sets out the structure, resources, communication, reporting and monitoring systems so that the management project will be consistent with the organisation vision [24]. Since the companies involved in PPP usually have a strong track record in development projects, it is believed that the best practice of project governance can be absorbed in PPP projects. In addition, private companies have no option but to scrutinise this aspect as project governance will influence the cost, speed of completion, quality and financial viability of project delivered [25].

The desire for design innovation of public facilities is well recognised. It is clearly shown when the injection of design innovation can be too complex for a certain types of building. In hospital for instance, there are changing patterns in medical care [26] as well as changing requirement for technologies, policies and services, which has made design innovation a challenging task [27]. Therefore, partnership with private sectors could help the government to handle these uncertainties. According to [28], innovation in design and management of public facilities is a factor driven by PPP implementation. Appropriate design innovation could generate savings in future maintenance and operational costs [22]. Thus, superior design innovation is expected from PPP scheme [29].

As PPP has introduced the long term approach, much anticipation has been given towards the services delivered in operational phase of PPP projects. Output specification, payment mechanism and monitoring, deduction of service failures performance are interrelated mechanisms in ensuring a high quality of service delivered under PPP projects [22]. The involvement of facilities management has also raised the quality expectation on service delivered. It is especially when facilities management has to handle lots of crucial aspects related to the operations and maintenance, project planning and management, communication, finance, quality assessment, facility function, human and environmental factors, space and workplace planning, budgeting, renovation or architectural planning and design [30].

In traditional delivery, government is responsible for all risks associated with the delivery of public facilities. PPP allows the government to transfer the risks to the private sectors. Risk transfer is one of the VfM key elements. According to [31], PPP is a medium transferring most of the risks to private parties yet deriving maximum VfM. Risk is transferred to private sectors that seem able to manage the risk better than the government [32]. This includes the risks arose from the building, operation, finance, and management of the PPP project. Therefore, PPP is considered a scheme that could lift the risk of burden bears by the government in delivering public facilities.

Earlier discussion has proved a strong rationale behind the implementation of PPP in delivering public facilities. PPP could improve both financial and nonfinancial aspect of public facilities. Studies from other countries have shown that there are benefits that successfully delivered and while some are not.

In French, [33] found that PPP projects performs well on issues such as respect of timetable and contracted prices but does not establish that PPP promotes innovation, quality of service delivery and life cycle costing. In accessing the experience of PFI in the UK's National Health Service, [34] has concludes that PFI provides no additional funding, do not deliver better 'value for money', create problems in affordability and increased cost of private finance to the public purse.

[35] have reviewed the elements of cost, quality, flexibility and complexity of PPP hospitals in Australia, Spain and UK. They found that the new facilities have been more expensive. The facilities are more likely to be built on time and within the budget, but at the expense of compromises on quality. The study concludes that PPP seem to further complicates the already difficult task of developing and managing hospital.

By adopting case study approach, [36] discovered that the first PPP hospital in Victoria shows that the hospital facility was built "within budget" and the government have indicate this cases evidence of successful implementation of the PPP policy. In Hong Kong, [37] found that non-privately funded PPP approach is more cost-effective and efficient in the delivery maintenance services. Both the public agent and service provider involve in the study perceive the non-privately funded PPP approach can allow higher flexibility, encourage innovation, enhance cost-effectiveness and improve the efficiency of work when compared with the traditional term contract in the delivery of maintenance services.

It was discovered that the PPP benefits are yet to be tested in Malaysian context. This paper is hence attempted to empirically verify these benefits. Next section will discuss how this study is conducted.

\subsection{Research method}

\subsection{Research instrument}

This study is embarked on quantitative methods. Similar to study conducted by [38] and [39], structured questionnaires were used to capture the perception of stakeholders on the topic of the present study. The questionnaire consists of four parts and this paper intends to report the first two parts. Part A consist of the demographic information of the respondents while Part B uses a Likert scale to measure the benefits of implementing PPP in delivering public facilities on a 
scale of $1-5$, where " 1 " is very disagree to " 5 " is very agree. Table 1 provides seven PPP benefits listed in the questionnaire.

Table 1. PPP benefits

\begin{tabular}{|cl|}
\hline No & PPP benefits \\
\hline 1. & $\begin{array}{l}\text { PPP leads to the optimum whole life costs of } \\
\text { public facilities. }\end{array}$ \\
2. & $\begin{array}{l}\text { PPP yields lower Capex and Opex compared to } \\
\text { traditional procurement. }\end{array}$ \\
3. & PPP allows faster delivery of projects \\
4. & PPP provides better project governance. \\
5. & PPP projects demonstrate innovative design \\
6. & PPpect. \\
7. & PPP allows transfer of risk to the parties that \\
& could manage it better.
\end{tabular}

\subsection{Questionnaire distribution and data collection}

The questionnaire survey was distributed to the respondents in a PPP healthcare conference conducted in Malaysia. This approach was adopted by Ismail and Haris [14] to investigate the factors that hinder the successful adoption of PPP in Malaysia. The chosen conference comprises of those who have knowledge, experience or at least interest on PPP scheme in Malaysia. Through the questionnaire, respondents are required to rate their agreements level on the benefits of PPP implementation in delivering public facilities in Malaysia. A total of 110 questionnaires were distributed to the participants. At the end of conference, 45 completed questionnaires were successfully collected representing a response rate of 40.9 per cent.

\subsection{Data analysis}

All 45 returned questionnaires were properly completed and analysed accordingly by using SPSS statistics software version 22. The demographic information of respondents were analysed using descriptive analysis and the mean score was used to rank the seven identified PPP benefits.

\subsection{Findings and discussions}

\subsection{Response rate and demographic information of the respondents}

Demographic information of the respondents is showed in Table 2. 47.7 per cent of the respondents are from the public sector whilst the remaining 53.3 per cent are from the private sector. In relation to working experience, majority of the respondents ( 75.5 per cent) have less than 5 years' experience in PPP projects. In term of number of PPP projects, 62.2 per cent of respondents have been involved in less than five projects and 37.8 per cent have experience in more than five projects. The demographic information of respondents has reflects their credibility in providing reliable data in the survey.

Table 2. Descriptive analysis of respondents

\begin{tabular}{|lc|}
\hline Respondents profile & $\begin{array}{c}\text { Proportion of the } \\
\text { sample response (\%) }\end{array}$ \\
\hline Working sectors & 47.7 \\
Public & 53.3 \\
Private & \\
& \\
Years of experience in PPP projects & 75.5 \\
Less than five years & 8.9 \\
5-10 years & 8.9 \\
11-15 years & 6.7 \\
More than 15 years & \\
& \\
Number of projects involved & 62.2 \\
Less than 5 & 37.8 \\
Five and more & \\
\hline
\end{tabular}

\subsection{Result on PPP benefits}

Table 3 reveals the frequency of response for each benefits of PPP implementation in delivering public facilities in Malaysia. The first two PPP benefits which are "PPP leads to the optimum whole life costs of public facilities" and "PPP yields lower Capex and Opex compared to traditional procurement" showed that the highest percentage of response is in 'Neutral' category. The answer of respondents was scattered among all five level of agreements. Meanwhile, the responses for the remaining five PPP benefits seem to be centralised at 'Agree' category. The answer of respondent for these non-financial PPP benefits were found to be scattered between 'Disagree' and 'Strongly Agree' categories, while no response fell into 'Strongly Disagree' categories.

Mean analysis was conducted to compare the listed benefits. As shown in Table 4, the mean score for the seven benefits range from $3.00-3.98$, which indicate there is different rank of each benefits. Table 4 show that in rank order, the PPP benefits that agreed by overall respondents were "improve quality of services", "innovative design", "transfer of risk", "faster delivery of projects" and "better project governance". All these benefits represent the non-financial PPP benefits. The result of analysis also showed that financial PPP benefits which are "optimum whole life cost" and "lower Capex and Opex" were neither agreed nor not agreed as the benefits of implementing PPP in Malaysia. Overall, the result indicates that all non-financial PPP benefits are recognised and agreed favourably by the respondent than non-financial PPP benefits. 
Table 3. PPP Benefits in Malaysia

\begin{tabular}{|c|c|c|c|c|c|c|c|c|c|c|}
\hline \multirow[t]{2}{*}{ PPP benefits } & \multicolumn{2}{|c|}{$\begin{array}{l}\text { Strongly } \\
\text { Disagree }\end{array}$} & \multicolumn{2}{|c|}{ Disagree } & \multicolumn{2}{|c|}{ Neutral } & \multicolumn{2}{|c|}{ Agree } & \multicolumn{2}{|c|}{$\begin{array}{l}\text { Strongly } \\
\text { agree }\end{array}$} \\
\hline & $n$ & $\%$ & $n$ & $\%$ & $n$ & $\%$ & $n$ & $\%$ & $n$ & $\%$ \\
\hline $\begin{array}{l}\text { 1. PPP leads to the optimum whole life } \\
\text { costs of public facilities. }\end{array}$ & 1 & 2 & 3 & 7 & 19 & 42 & 18 & 40 & 4 & 9 \\
\hline $\begin{array}{l}\text { 2. PPP yields lower Capex and Opex } \\
\text { compared to traditional procurement. }\end{array}$ & 2 & 4 & 12 & 27 & 16 & 36 & 14 & 31 & 1 & 2 \\
\hline 3. PPP allows faster delivery of projects & - & - & 3 & 7 & 12 & 27 & 22 & 49 & 8 & 18 \\
\hline 4. PPP provides better project governance. & - & - & 2 & 4 & 13 & 29 & 26 & 58 & 4 & 9 \\
\hline $\begin{array}{l}\text { 5. PPP projects demonstrate innovative } \\
\text { design aspect. }\end{array}$ & - & - & 2 & 4 & 8 & 18 & 26 & 58 & 9 & 20 \\
\hline $\begin{array}{l}\text { 6. PPP improves the quality of services } \\
\text { delivered. }\end{array}$ & - & - & 1 & 2 & 6 & 13 & 31 & 69 & 7 & 16 \\
\hline $\begin{array}{l}\text { 7. PPP allows transfer of risk to the parties } \\
\text { that could manage it better. }\end{array}$ & - & - & 2 & 4 & 10 & 22 & 25 & 56 & 8 & 18 \\
\hline
\end{tabular}

Table 4. Mean and rank of PPP benefits in Malaysia

\begin{tabular}{|llc|}
\hline PPP benefits & Mean & Ranking \\
\hline $\begin{array}{l}\text { 1.PPP improves the quality of } \\
\text { services delivered. }\end{array}$ & 3.98 & 1 \\
2.PP projects demonstrate & 3.93 & 2 \\
innovative design aspect. & & \\
3. PPP allows transfer of risk & 3.87 & 3 \\
to the parties that could & & \\
manage it better. & & \\
4. PPP allows faster delivery of & 3.78 & 4 \\
projects & & \\
5. PPP provides better project & 3.71 & 5 \\
governance. & & \\
6. PPP leads to the optimum & 3.47 & 6 \\
whole life costs of public & & \\
facilities. & & \\
7. PPP yields lower Capex and & 3.00 & 7 \\
Opex compared \\
traditional procurement.
\end{tabular}

The benefits "improves the quality of services" (mean $=3.98$ ) has secured the first place thus perceived as the top benefits of PPP implementation in Malaysia. It was expected that PPP will give a positive impact on the quality of services the most. The reformation of facilities management involvement, which is since in the development phase of PPP project, has led to a significant improvement on the quality of services. In contrast, study by [33] found that this benefits cannot be enjoyed in French.

"Design innovation" (mean $=3.93)$ has ranked as the second benefits in implementing PPP in Malaysia. Nevertheless, this advantage is facing lots of criticism in other countries. In contrast, [27] claimed that PPP was less effective in stimulating design innovation desired by the UK government. Design innovation has also showed a slower progress than process innovation in PPP projects [22]. Considering Malaysia as a developing country and existing design flaws in traditional procurement of public facilities, it is possible for design aspect to improve a lot by the implementation of PPP.

The third benefit of PPP implementation in Malaysia is "transfer of risk to the parties that could manage it better" (mean=3.87). The transfer of some risks, operational and maintenance for instance allow the government to focus on their other core business. Besides, [13] claimed that the encouragement to use Islamic financing in implementing PPP/PFI projects in Malaysia may lead to new perceptive towards the concept of risk transfer and improved risk sharing.

The benefits in terms of cost are less prominent compared to other benefits. In other study, [40] have put cost as the main disadvantage of PPP projects. According to [21], the ability to deliver project at a lower cost depends on private sector partner having the appropriate incentive. This is due to the interest of private, which usually aims for profit maximisation and not cost minimisation. More effort should be taken by the PPP stakeholder to boost financial benefits of PPP implementation. One of the solutions is by running a competitive process that usually offers a better solution at a lower cost [41].

\subsection{Conclusion}

The study used a questionnaire survey to investigate PPP benefits in delivering public services in Malaysia. Most of the benefits were obtained through private sectors efficiency. The overall results show that "PPP improves the quality of services delivered", "PPP projects demonstrate innovative design aspect" and "PPP allows transfer of risk to the parties that could manage it better" are the top three PPP benefits in Malaysia.

However, there are a few limitations in this study that should be highlighted in order to ensure a fair interpretation of the findings. First, the finding of this is solely based on the perception of local PPP stakeholders. Future studies may consider using other dimension or indicators such as monetary, customer satisfaction etc. to measure the PPP benefits. Second, the used of general questionnaire may not be the best option to grasp the real impact of PPP for specific type of projects. Therefore, case study approach is highly recommended as different projects may show different results. Third, the selection 
of conference as a medium to approach the sample of study has limited the number of response. In this case, [14] claimed that it would be better to increase the sample size and distribute the survey instrument to larger geographical area or more seminars.

In conclusion, despite the limitations, this study has filling the gap of existing literature in regards to PPP implementation in Malaysia. In particular, this study expose the perception of public and private sectors in regards to PPP benefits in delivering public facilities in Malaysia. The findings has portrayed the impact of PPP and justified the use of this scheme in the future.

\section{Acknowledgement}

This research is supported by the Ministry of Education, Malaysia under Fundamental Research Grant Projects (FRGS) (VOT: 4F633).

\section{References}

1. Kinder, C. and D. Wright, Better Public service Delivery Through Public-Private Partnerships: A New Approach to Infrastructure Development. (2009), Commonwealth Business School and International Financial Services, London (IFSL).

2. Cruz, C.O. and R.C. Marques, Infrastructure PublicPrivate Partnerships: Decision, Management and Development. (2013): Springer Berlin Heidelberg.

3. Yescombe, E.R., Public-Private Partnerships: Principles of Policy and Finance. (2011), Butterworth-Heinemann: Elsevier Science.

4. Shen, L.-Y., A. Platten, and X.P. Deng, Role of public private partnerships to manage risks in public sector projects in Hong Kong. INT J PROJ MANAGE, (2006). 24(7): p. 587-594.

5. Cheung, E., A.P.C. Chan, and S. Kajewski, Reasons for implementing public private partnership projects: Perspectives from Hong Kong, Australian and British practitioners. JPIF, (2009). 27(1): p. 81-95.

6. Takim, R., et al., The Malaysian Private Finance Initiative and Value for Money. Asian social science, (2009). 5(3): p. P103.

7. Public Private Partnership Unit, Public Private Partnership Guideline, P.M.D. Public Private Partnership Unit, Editor. (2009): Malaysia.

8. Beh, L.S., Development and Distortion of Malaysian Public-Private Partnerships-Patronage, Privatised Profits and Pitfalls. AJPA, (2010). 69(s1): p. S74S84.

9. Ismail, S., Critical success factors of public private partnership (PPP) implementation in Malaysia. APJBA (2013). 5(1): p. 6-19.

10. Ninth Malaysia Plan, Ninth Malaysia Plan (20062010). 2006, Economic Planning Unit: Malaysia.

11. Ismail, S. and F.A. Haris, Rationales for public private partnership (PPP) implementation in Malaysianull. JFMPC, 2014. 19(3): p. 188-201.

12. Ismail, S., Factors attracting the use of public private partnership in Malaysia. JCDC, (2013). 18(1): p. 95108.
13. Abdullah, N., et al. PPP/PFI in Malaysian Development Plans: Purpose, Structure, Implementation, Financing and Risk Transfer. in Proceedings of 5th Asia-Pacific Business Research Conference. (2014). Hotel Istana, Kuala Lumpur, Malaysia.

14. Ismail, S. and F.A. Haris, Constraints in implementing Public Private Partnership (PPP) in Malaysia. Built Environment Project and Asset Management, (2014). 4(3): p. 238-250.

15. Ismail, S. What Drives Value for Money of Public Private Partnership (PPP) Projects Implementation in Malaysia? in Persidangan Kebangsaan Ekonomi Malaysia (PERKEM VII). (2012). Perak, Malaysia.

16. Takim, R., K. Ismail, and A.H. Nawawi. A value for money assessment method for Public Private Partnership: A lesson from Malaysian approach. in International Conference on Economic and Finance research. 2011. Singapore.

17. El-Haram, M.A., S. Marenjak, and M.W. Horner, Development of a generic framework for collecting whole life cost data for the building industry. JQME, (2002). 8(2): p. 144-151.

18. Akintoye, A., M. Beck, and C. Hardcastle, PublicPrivate Partnerships: Managing Risks and Opportunities. (2003): Wiley.

19. Siemiatycki, M. and N. Farooqi, Value for Money and Risk in Public-Private Partnerships. JAPA, (2012). 78(3): p. 286-299.

20. Grimsey, D. and M. Lewis, Public Private Partnerships: The Worldwide Revolution in Infrastructure Provision and Project Finance. (2007): Edward Elgar.

21. Boardman, A., F. Poschmann, and A. Vining, North American infrastructure P3s: examples and lessons learned. The Challenge of Public-Private Partnerships: Learning from International Experience, (2005): p. 162-189.

22. Robinson, H., et al., Governance and Knowledge Management for Public-Private Partnerships. (2009): Wiley.

23. U.S. Department of Transportation, Report to Congress on the Costs, Benefits, and Efficiencies of Public-Private Partnerships for Fixed Guideway Capital Projects. (2007), U.S. Department of Transportation: Washington, DC.

24. Kumaraswamy, M., et al., A review of Australian PPP governance structures. JFMPC, (2010). 15(3): p. 198215.

25. Patel, M. and H. Robinson, Impact of governance on project delivery of complex NHS PFI/PPP schemes. JFMPC, (2010). 15(3): p. 216-234.

26. Cruz, C.O. and R.C. Marques, Integrating Infrastructure and Clinical Management in PPPs for Health Care. J. Manage. Eng., (2013). 29(4): p. 471 481.

27. Barlow, J. and M. Köberle-Gaiser, The private finance initiative, project form and design innovation: The UK's hospitals programme. Research Policy, (2008). 37(8): p. 1392-1402.

28. Alshawi, M., Concept and background to Public Private Partnership / Private Finance Initiative - UK 
Experience. 2009, Iraq Institute for Economic Reforms (IIER).

29. Raisbeck, P., Considering design and PPP innovation: $A$ review of design factors in PPPresearch, in Procs 25th Annual ARCOM Conference, A. Dainty, Editor. (2009), he Association of Researchers in Construction Management p. 23947.

30. El-Haram, M.A. and A. Agapiou, The role of the facility manager in new procurement routes. JQME, (2002). 8(2): p. 124.

31. Doloi, H., Understanding impacts of time and cost related construction risks on operational performance of PPP projects. INT J STRATEG PROP M, (2012). 16(3): p. 316-337.

32. Ling, F.Y.Y., et al., Public Private Partnerships: Overcoming Pre-Contract Problems Faced by Public Clients and Private Providers in Infrastructure Projects in Singapore. IJCM, (2011). 11(1): p. 63-77.

33. Bougrain, F., Energy performance and public private partnership. BEPAM, (2012). 2(1): p. 41-55.

34. Liebe, M. and A.M. Pollock, The experience of the private finance initiative in the UK's National Health Service. (2009), The Centre for International Health Policy, The University of Edinburgh: Edinburgh.

35. McKee, M., N. Edwards, and R. Atun, Public-private partnerships for hospitals. Bulletin of the World Health Organization, (2006). 84(11): p. 890-896.

36. Sciulli, N., Public private partnerships: an exploratory study in health care. Asian Review of Accounting, (2008). 16(1): p. 21-38.

37. Ng, S.T. and Y.M.W. Wong, Adopting non-privately funded public-private partnerships in maintenance projects: A case study in Hong Kong. ECAM, (2006). 13(2): p. 186-200.

38. Li, B., et al., Perceptions of positive and negative factors influencing the attractiveness of PPP/PFI procurement for construction projects in the UK: Findings from a questionnaire survey. ECAM, (2005). 12(2): p. 125-148.

39. Babatunde, S.O., et al., Stakeholder perceptions on critical success factors for public-private partnership projects in Nigeria. BEPAM, (2016). 6(1): p. 74-91.

40. Eadie, R., P. Millar, and R. Grant, PFI/PPP, private sector perspectives of $U K$ transport and healthcare. BEPAM, (2013). 3(1): p. 89-104.

41. ICA Secretariat, Attracting Investors to African Public-private Partnerships: A Project Preparation Guide. World Bank e-Library. (2009), Washington DC: World Bank. 